\title{
APLIKASI SISTEM INFORMASI PARIWISATA TOURISM PADA DKI JAKARTA BERBASIS ANDROID
}

\author{
Mohamad Natsir \\ Fakultas Ilmu Komputer Universitas Mercu Buana Jakarta \\ Jalan Meruya Selatan No. 1, Meruya Selatan, Kembangan, Jakarta Barat, \\ Daerah Khusus Ibukota Jakarta 11650 \\ E-mail : m.natsir@mercubuana.ac.id
}

\begin{abstract}
DKI Jakarta has many characteristics both in terms of attractions, culture, crafts and culinary. Jakarta is an attractive capital city and is often visited by tourists from various regions and abroad. So from that writing makes an application about tourist information in the City of Jakarta based on Android. Users of this application are expected to easily find tourist information in the city of Jakarta. Information contained in the application in the form of tourist attractions. The application also displays the direction of the location to that place using the Global Possitioning System (GPS) connection. The method used in this application is to contain information and location of each place in the city of Jakarta such as tourist attractions. Each menu selected has information and directions to reach the desired place. This application is only used on Androidbased smartphones and the screen size is less than 4.0 inches, besides the size of 4.0 inches this application is not good at displaying tourist information.
\end{abstract}

Keywords: DKI Jakarta, Indonesia, tourism, android, GPS

\begin{abstract}
ABSTRAK
DKI Jakarta memiliki banyak ciri khas baik dari segi objek wisata, Budaya, Kerajinan dan Kuliner. Jakarta adalah Ibu Kota yang menarik dan sering dikunjungi oleh wisatawan dari berbagai Daerah maupun mancanegara. Maka dari itu penulisan membuat suatu aplikasi mengenai informasi wisata yang ada di Kota Jakarta berbasis Android. Pengguna aplikasi ini diharapkan dapat dengan mudah untuk mencari informasi wisata yang ada di Kota Jakarta. Informasi yang terdapat dalam aplikasi berupa tempat wisata. Aplikasi juga menampilkan arah lokasi ke tempat tersebut dengan menggunakan koneksi Global Possitioning System (GPS). Metode yang dipakai pada aplikasi ini yaitu berisikan informasi dan letak dari setiap tempat yang ada di Kota Jakarta seperti tempat wisata. Setiap menu yang dipilih terdapat informasi dan petunjuk arah untuk mencapai tempat yang diinginkan. Aplikasi ini hanya digunakan pada smartphone berbasis Android dan berukuran layar kurang dari 4.0 inchi, selain ukuran 4.0 inchi aplikasi ini kurang bagus pada tampilan informasi objek wisata.
\end{abstract}

Kata kunci: DKI Jakarta, Indonesia, pariwisata, android, GPS 


\section{JURNAL PETIR}

Vol. 12, No. 1, Maret 2019, P-ISSN 1978-9262, E-ISSN 2655-5018

\section{PENDAHULUAN}

Pengembangan sistem informasi dalam kurun waktu kini sungguh sangat pesat. Hampir setiap perusahaan selalu melakukan perbaikan, inovasi dan evaluasi terhadap sistem informasi yang ada di dalam perusahaan tersebut, agar selalu mendukung bisnis-bisnis yang mereka jalankan. Dengan memanfaatkan kemampuan dari sistem informasi, diharapkan perkembangan bisnis semakin maju dan dapat menaikkan pendapatan dari perusahaan.

Saat ini Jakarta dikenal sebagai ibu kota dengan populasi tertinggi di Indonesia, namun Jakarta masih menyimpan pesonanya sendiri. Jakarta secara umum merupakan kota metropolitan terbesar di Asia Tenggara, dengan jumlah penduduk lebih dari 10 (sepuluh) juta jiwa, hal itu menjadikan ibukota Jakarta sebagai kota yang padat penduduk. Jakarta juga menjadi pusat pemerintah, pusat bisnis, dan pusat kebudayaan. Ada banyak tempat wisata di Jakarta yang menarik untuk di kunjungi namun tidak semua wisatawan mengetahui akan hal tersebut. Beberapa tempat wisata di Jakarta seperti Monumen Nasional atau Tugu Monas, Ancol, Taman Mini Indonesia Indah, Kota Tua, dan sebagainya.

Tidak sedikit masyarakat indonesia, dalam mecari tahu tempat wisata wilayah DKI Jakarta masih menggunakan mesin pencari atau yang biasa kita ketahui dengan sebutan Google. Menanggapi hal tersebut tentunya masyarakat akan di hadapkan dengan banyak nya pilihan dari hasil mesin pencari tersebut dimana itu akan membuat masyarakat sedikit bimbang dalam menentukan pilihan, dan tidak semuanya dapat diketahui oleh wisatawan dikarenakan kurangnya informasi mengenai lokasi tempat wisata itu berada, akomodasi seperti hotel atau wisma terdekat, beserta kuliner yang berada di sekitar objek wisata tersebut. Selain itu, para wisatawan juga lebih suka menggunakan sistem informasi yang sederhana dan interaktif dengan tampilan yang menarik.

1.1 Identifikasi Masalah

a) Belum adanya melakukan pendaftaran anggota baru dengan menggunakan aplikasi mobile.

b) Belum adanya user untuk melakukan pencarian tempat wisata dengan menggunakan aplikasi mobile.

c) Belum adanya menentukan tempat wisata yang paling banyak disukai oleh masyarakat dalam aplikasi mobile.

d) Belum adanya cara user untuk dapat memberikan penilaian dan komentar terhadap tempat wisata yang ada dalam aplikasi mobile.

1.2 Batasan Masalah

a) Proses pendaftaran anggota baru atau registrasi

b) Proses pencarian tempat wisata

c) Proses pencarian tempat wisata berdasarkan penilaian user.

d) Proses pemberian penilaian dan komentar pada tempat wisata.

e) Proses perancangan aplikasi berbasis android.

\subsection{Tujuan Penelitian}

a) Untuk memudahkan penilaian hasil kerja karyawan.

b) Mengidentifikasi permasalahan dalam sistem penilaian kinerja karyawan.

c) Merancang dan membuat program untuk sistem penilaian kinerja karyawan guna meningkatkan efisiensi kerja pada Perusahaan.

\section{METODE DAN PERANCANGAN SISTEM}

Perancangan sistem ini akan dibangun dengan aplikasi berbasis mobile, dimana wisatawan dapat melihat informasi tentang pariwisata yang ada di DKI Jakarta dengan praktis tidak perlu membuka web browser, dan perancangan sistem ini juga akan dibangun dengan aplikasi berbasis web, dimana ada admin yang bertugas untuk menginput data yang nantinya akan tersimpan di database server dan wisatawan dapat melihat informasi pariwisata tersebut melalui aplikasi berbasis mobile. 
Pada tahap perancangan sistem ini digunakan UML (Unified Modeling Language) untuk memenuhi semua kebutuhan sistem dan menjelaskan proses-proses yang akan terjadi pada aplikasi. Diagram yang digunakan dalam desain perancangan aplikasi ini antara lain use case diagram, activity diagram, class diagram dan sequence diagram.

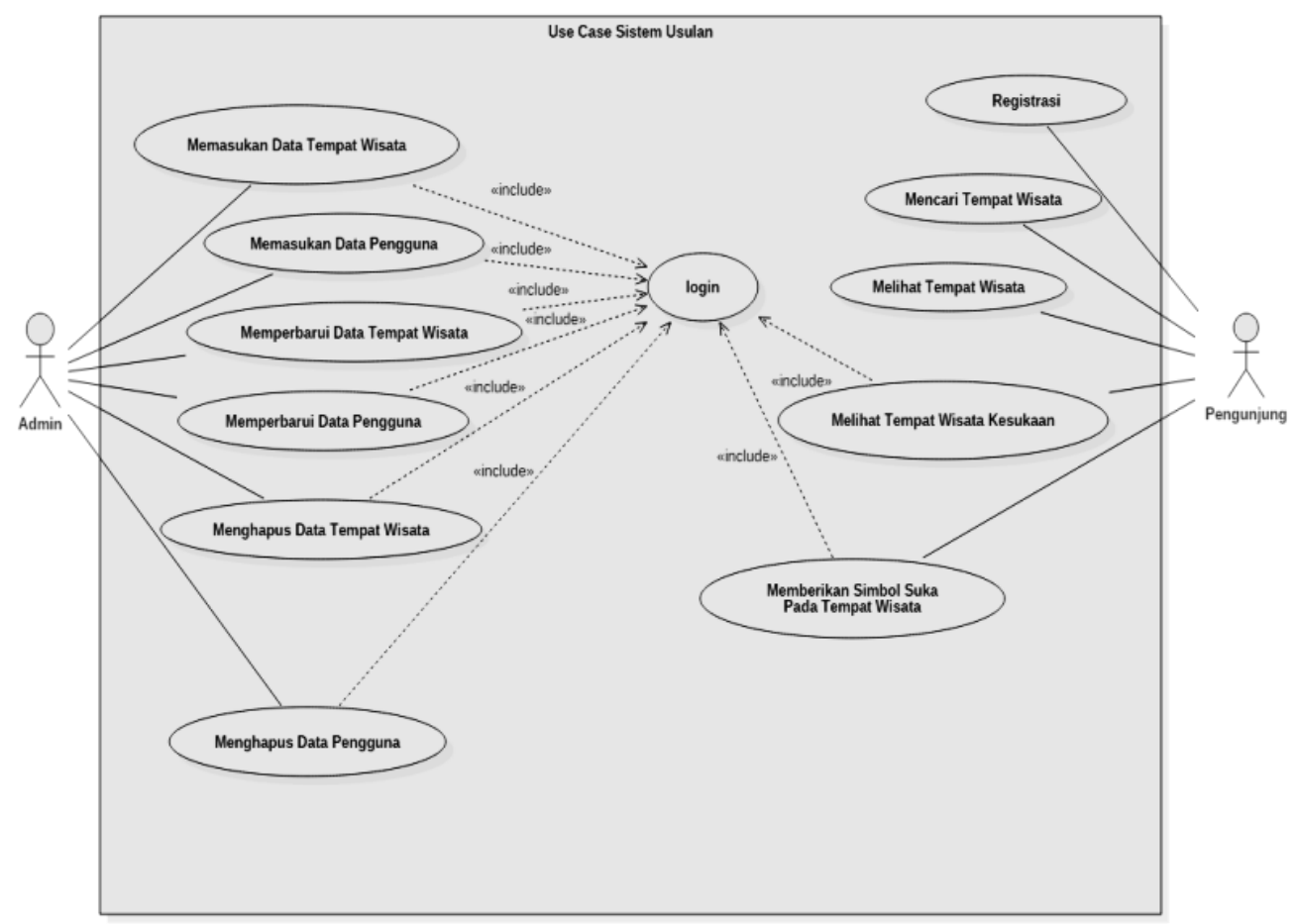

Gambar 1. Use Case Aplikasi Sistem Berjalan

Berdasarkan use case diagram yang telah dirancang, maka dapat digambarkan activity diagram berikut ini:

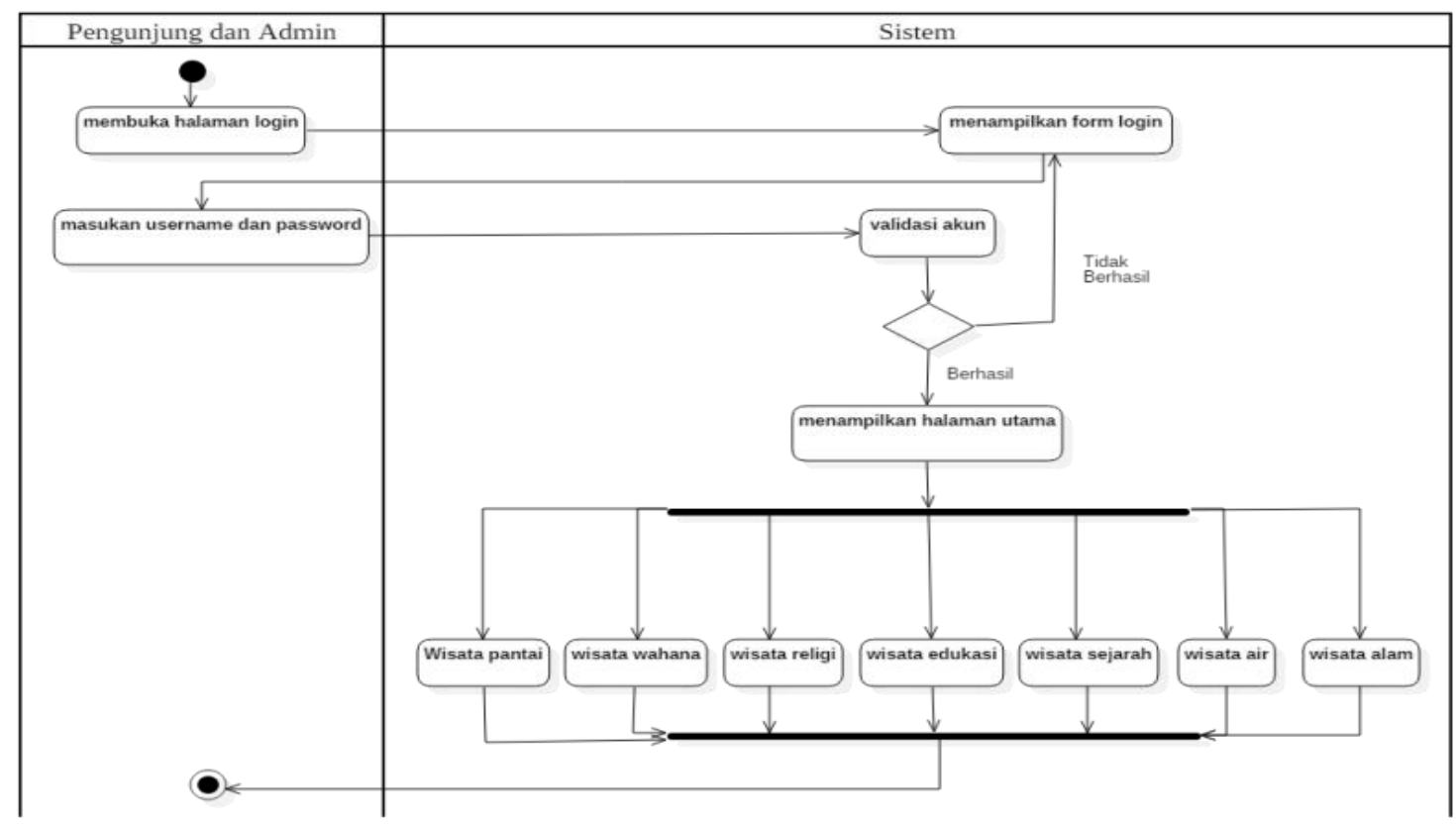

Gambar 2. Activity Diagram Login 


\section{Sequence Diagram Memasukan Data Wisata}

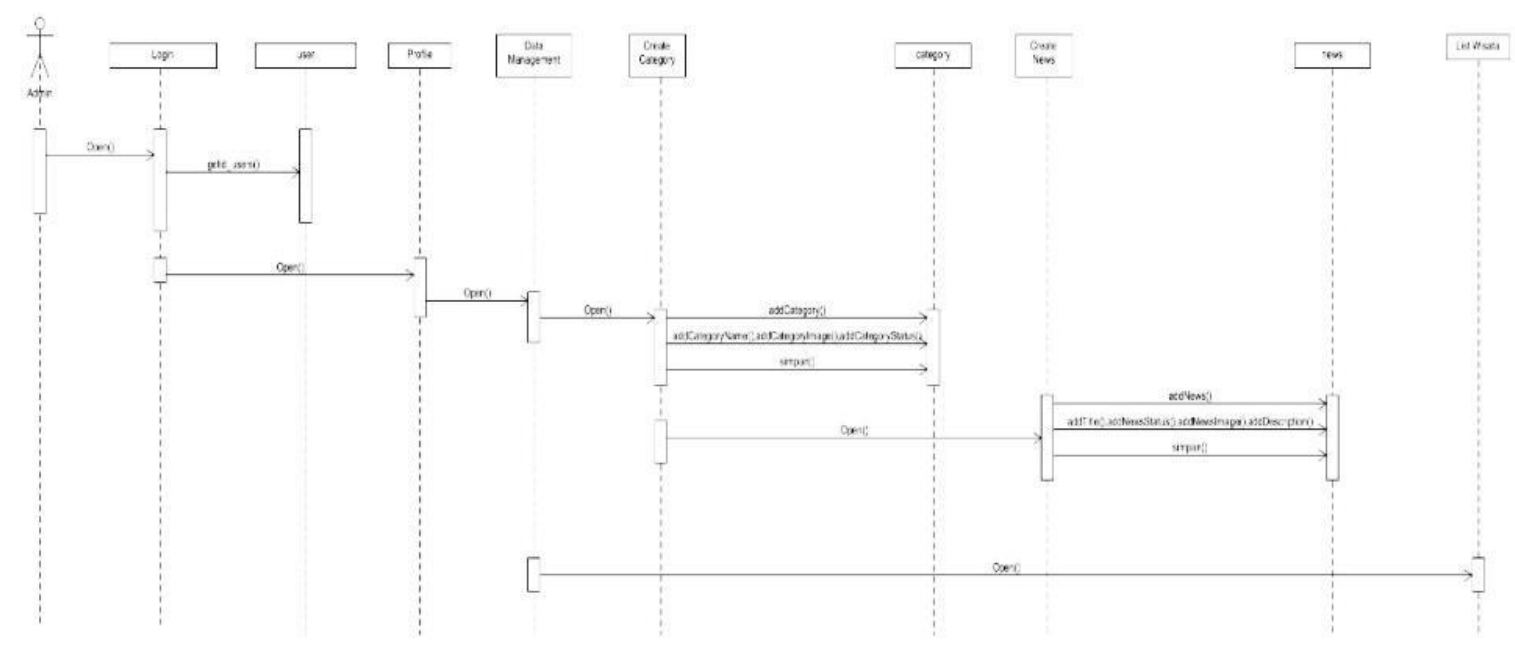

Gambar 3. Sequence Diagram Memasukan Data Wisata

Class diagram merupakan kumpulan dari class - class yang saling berhubungan atau berelasi secara struktural. Class diagram mendeskripsikan jenis - jenis objek dalam sistem dan berbagai macam hubungan statis yang terjadi.

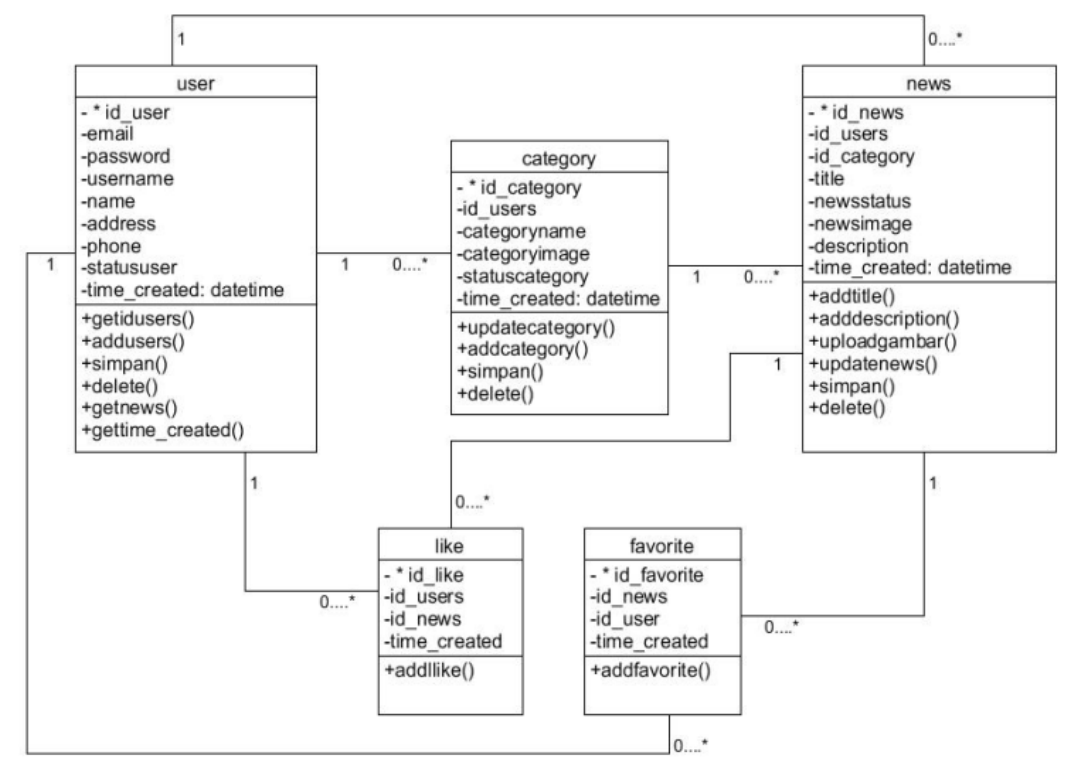

Gambar 4. Class Diagram

\section{HASIL DAN PEMBAHASAN}

Implementasi merupakan kelanjutan dari kegiatan perancangan sistem dan dapat dipandang sebagai usaha untuk mewujudkan sistem yang dirancang. Pada tahapan ini proses yang dilakukan adalah implementasi dan pengujian dari sistem yang sudah dirancang. Hasil dari tahapan ini adalah suatu sistem pengolahan data dan informasi yang sudah berjalan dengan baik.

\subsection{Cara Pengoperasian Aplikasi}

1. Pengguna dan Admin Sebelum Login

A. Layar Depan Aplikasi Sebelum Login 


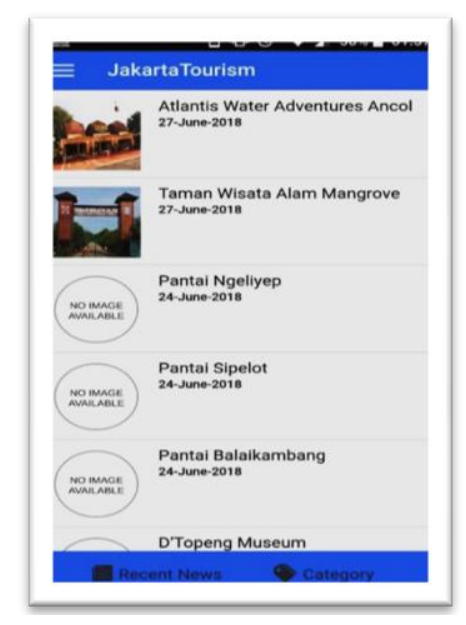

Gambar 5. Layar Depan Aplikasi Sebelum Login

\section{B. Menu Aplikasi Sebelum Login}

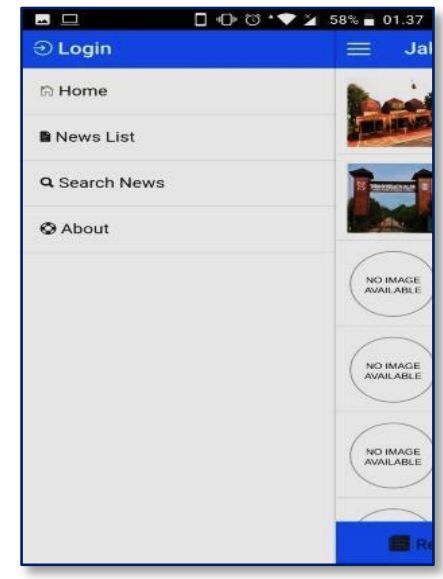

Gambar 6. Layar Depan Aplikasi Sebelum Login

\section{Menu Aplikasi Sebelum Login}

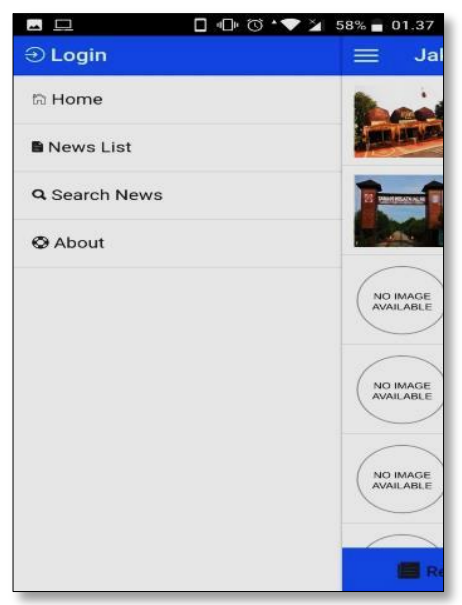

Gambar 7. Layar Depan Aplikasi Sebelum Login

Pada halaman menu aplikasi user dan admin hanya dapat melihat list wisata dan bisa memulai login. 


\section{Layar Detail Wisata Sebelum Login}
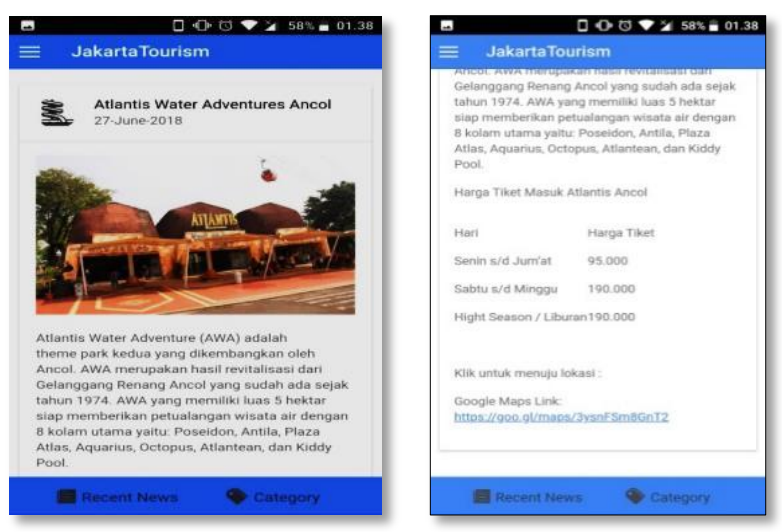

Gambar 8. Layar Detail Wisata Sebelum Login

Gambar 8 adalah layar detail wisata sebelum login hanya untuk melihat wisata secara detail tidak bisa memberikan favorite dan like.

\section{E. Layar Menu Login}

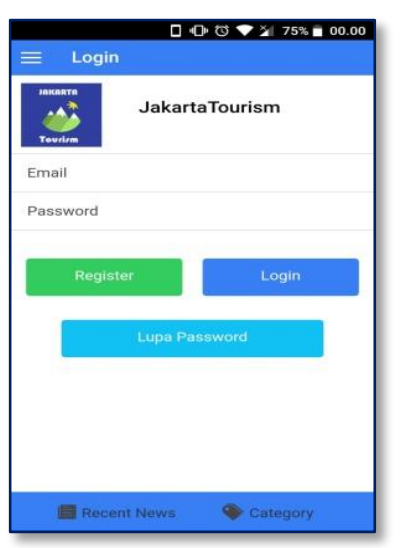

Gambar 9. Layar Menu Login

\section{F. Layar Depan Setelah Login}

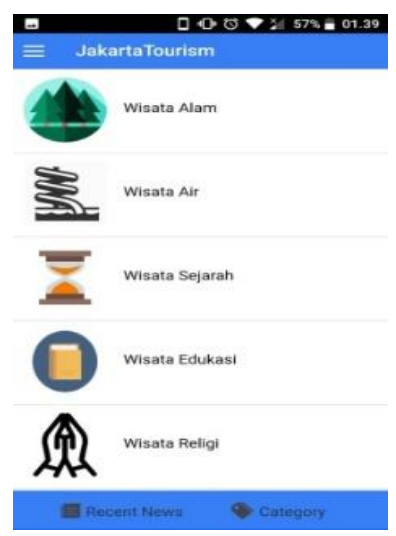

Gambar 10. Layar Depan Setelah Login

Layar depan setelah login sebagai pengguna, pengguna memiliki menu wisata alam, wisata air, wisata sejarah, wisata edukasi, wisata religi. 
G. Layar Menu Pengguna

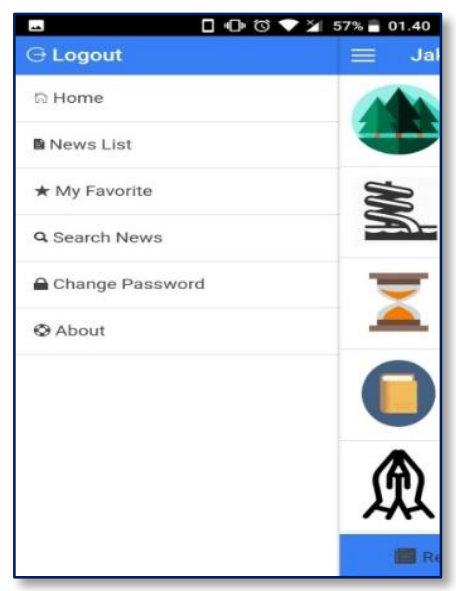

Gambar 11. Layar Menu Penggun

H. Layar Map Wisata

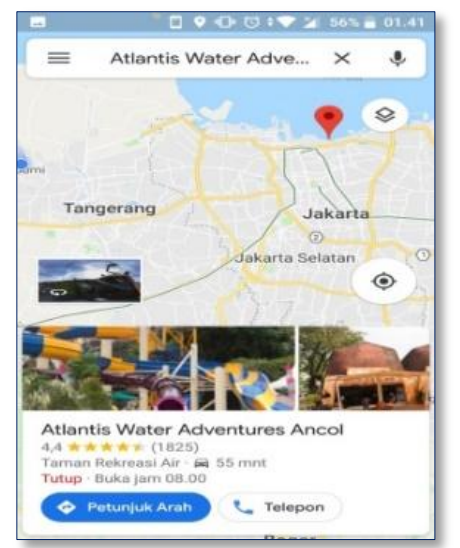

Gambar 12. Layar Map Wisata

I. Layar Edit Dan Delete

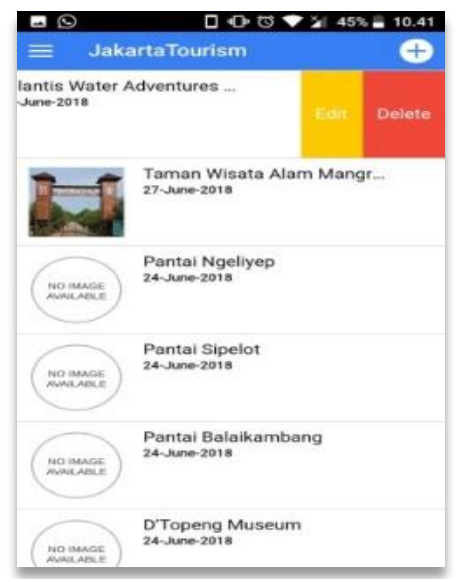

Gambar 13. Layar Edit Dan Delete 


\section{J. Layar Menambahkan Berita}

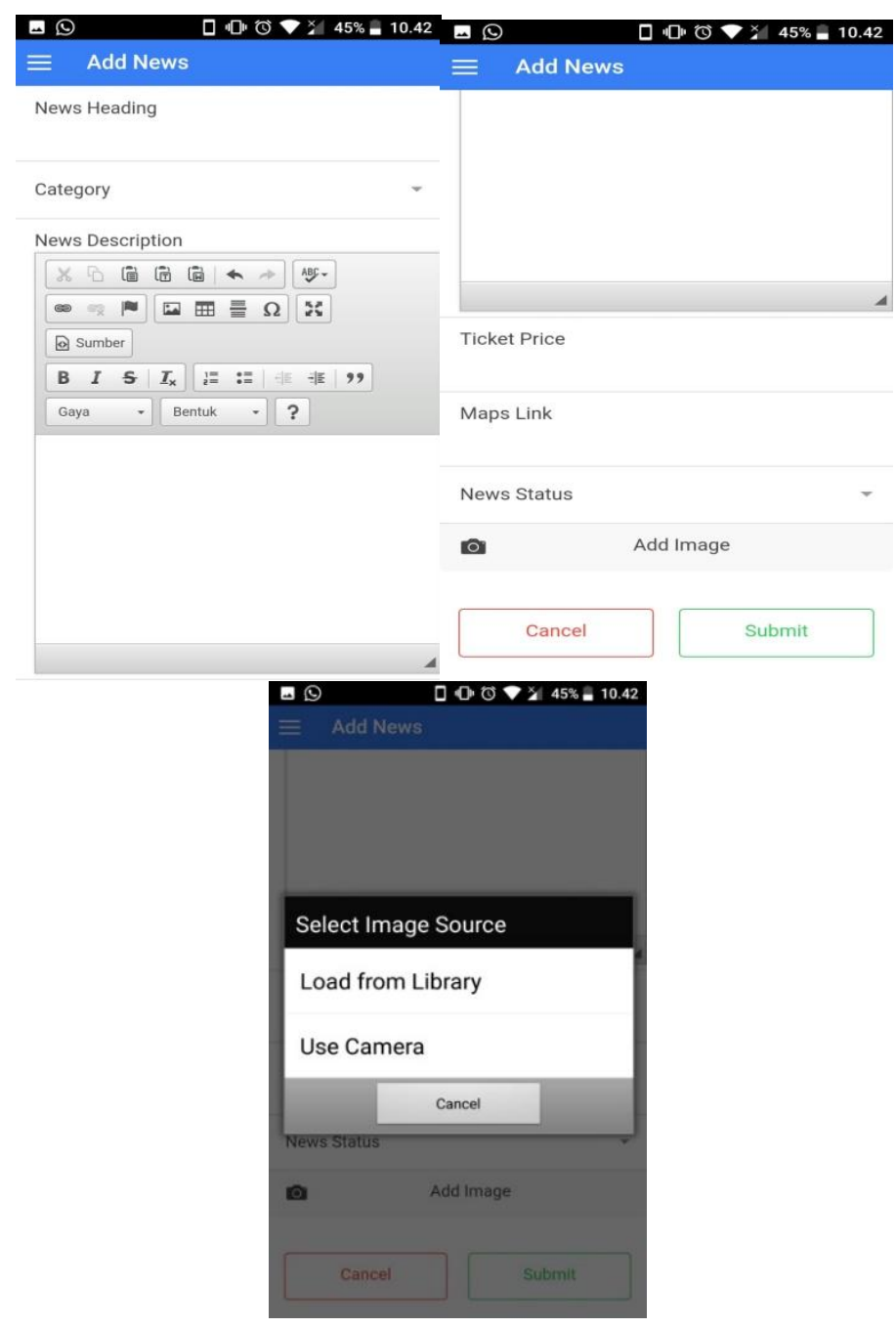

Gambar 14. Layar Menambahkan Berita

\section{Skenario Pengujian}

Tabel 1. Identifikasi Rencana Pengujian Perangkat Lunak

\begin{tabular}{|c|l|l|l|l|l|}
\hline No. & $\begin{array}{l}\text { Antar } \\
\text { Muka } \\
\text { Yang } \\
\text { Diuji }\end{array}$ & \multicolumn{1}{|c|}{$\begin{array}{c}\text { Proses Yang } \\
\text { Diuji }\end{array}$} & $\begin{array}{c}\text { Status } \\
\text { Aplikasi }\end{array}$ & Skenario Pengujian & Hasil \\
\hline 1 & $\begin{array}{l}\text { Halaman } \\
\text { Menu } \\
\text { Home }\end{array}$ & $\begin{array}{l}\text { Proses } \\
\text { menampilkan } \\
\text { menu wisata }\end{array}$ & $\begin{array}{l}\text { Halaman } \\
\text { Menu Home } \\
\text { sudah terbuka }\end{array}$ & $\begin{array}{l}\text { Setelah menampilkan } \\
\text { halaman splash } \\
\text { screen, kemudian } \\
\text { menu Home tampil }\end{array}$ & $\begin{array}{l}\text { Berhasil } \\
\text { menampilkan menu } \\
\text { wisata }\end{array}$ \\
\hline 2 & $\begin{array}{l}\text { Halama } \\
\text { Register }\end{array}$ & $\begin{array}{l}\text { Menguji proses } \\
\text { pendaftaran }\end{array}$ & $\begin{array}{l}\text { Tampilan } \\
\text { form } \\
\text { pendaftaran }\end{array}$ & $\begin{array}{l}\text { Isi data pendaftaran } \\
\text { pengguna, lalu input } \\
\text { data }\end{array}$ & $\begin{array}{l}\text { Berhasil melakukan } \\
\text { pendaftaran, lalu } \\
\text { masuk ke halaman } \\
\text { utama }\end{array}$ \\
\hline
\end{tabular}




\section{KESIMPULAN DAN SARAN}

\subsection{Kesimpulan}

Berdasarkan analisa dan perancangan pada aplikasi mobile berbasis android, dibawah ini merupakan kesimpulan yang diperoleh :

Aplikasi sistem informasi wisata Jakarta ini dapat diakses langsung oleh pengguna atau wisatawan.Terdapat fitur navigasi yang memudahkan wisatawan untuk menjangkau lokasi wisata. Terdapat fitur Favorite yang memudahkan masyarakat untuk mengingat lokasi wisata yang disukainya.Dengan adanya sistem informasi pariwisata di Jakarta ini diharapkan dapat membantu wisatawan dalam berkunjung ke Jakarta dan mendapatkan informasi wisata di Jakarta.

\subsection{Saran}

Saran yang dapat dijadikan panduan dalam pengembangan selanjutnya adalah dapat ditambahkan informasi seperti transportasi yang menuju ke lokasi wisata tersebut. Mengembangkan aplikasi ini pada platform lain yang ada dipasaran. Dapat ditambahkan fitur untuk wisatawan agar dapat memberikan komentar tentang wisata yang telah dikunjungi,

\section{DAFTAR PUSTAKA}

[1] Rosa A.S dan M.Shalahuddin. (2016.), Rekayasa Perangkat Lunak Terstruktur Dan Berorientasi Objek. Bandung: Informatika.

[2] Safaah, Nazarudin. (2016). Pemrograman Aplikasi Mobile Smartphone Dan Tablet PC Berbasis Android. Bandung: Informatika.

[3] Dodit Suprianti dan Rini Agustina. (2016). Pemrograman Aplikasi Android. Yogyakarta: MediaKom.

[4] Juhara, Zamrony P. ((2016). Panduan Lengkap Pemrograman Android. Yogyakarta: Andi Publisher.

[5] Sutaman. (2012). Pengantar Teknologi Informasi. Jakarta: Bumi Aksara. Dennis, Buana, I Komang Setia. (2014). Jago Pemrograman PHP. Jakarta: Dunia Komputer.

[6] Kusumawijaya, Marco. (2014). Jakarta Metropolis Tunggang-Langgang. Jakarta: GagasMedia.

Haruwu, Dermawan. (2018). Bawomataluo Destinasi Wisata Nias Pulau Impian. Yogyakarta: Deepublish. 